\title{
Persepsi Lingkungan Kerja Fisik dengan Employee Engagement pada Karyawan
}

\author{
Ony Sholikhatun Rukmi Putri', Sowanya Ardi Prahara ${ }^{2}$ \\ ${ }^{12}$ Fakultas Psikologi, Universitas Mercu Buana Yogyakarta, \\ Jl. Raya Wates Km. 10, Karanglo, Argomulyo, Kec. Sedayu, Bantul, Daerah Istimewa Yogyakarta 55752 \\ 1analutfi090795@gmail.com, ${ }^{2}$ sowanya_hara@yahoo.com
}

\begin{abstract}
Abstrak
Penelitian ini bertujuan untuk mengetahui hubungan antara persepsi lingkungan kerja fisik dengan employee engagement pada karyawan. Hipotesis dalam penelitian ini adalah terdapat hubungan positif antara persepsi lingkungan kerja fisik dengan employee engagement pada karyawan. Responden dalam penelitian ini adalah karyawan bagian produksi yang sudah bekerja minimal 6 bulan, berstatus karyawan tetap, dan berusia 21-40 tahun sebanyak 53 karyawan dengan sampling purporsive. Skala Employee Engagement dan Skala Persepsi Lingkungan Kerja Fisik digunakan sebagai alat ukur, yang selanjutnya data dianalisis dengan korelasi product moment. Didapatkan nilai koefisien korelasi sebesar $0.650(\mathrm{p}<0.005)$. hal ini menunjukkan ada hubungan positif yang signifikan antara persepsi lingkungan kerja fisik dengan employee engagement pada karyawan.
\end{abstract}

Kata kunci : persepsi lingkungan kerja fisik, employee engagement, karyawan

\begin{abstract}
This study discusses the relationship between the perception of the physical work environment with work engagement on employees. The hypothesis in this study is that there is a positive relationship between the perception of the physical work environment with work engagement on employees. Respondents in this study were employees of the production department who had worked for at least 6 months, had permanent employees, and aged 21-40 years as many as 53 employees with purposive sampling. The work engagement scale and the Perception Scale of the Physical Work Environment are used as a measurement tool, then the data are analyzed using product moment correlation. Obtained correlation coefficient value of $0.650(p<0.005)$. this shows there is a significant positive relationship between the perception of the physical work environment with work engagement on employees.
\end{abstract}

Keywords: perception of physical work environment, employee engagement, employees

\section{PENDAHULUAN}

Menurut Novitasari, Jayanti, dan Ekawati (2015) karyawan bagian produksi mengalami kelelahan kerja. Hal ini disebabkan karena jadwal shift dan aktivitas yang cukup padat. Kelelahan kerja yang disebabkan oleh beban kerja yang tinggi dapat meningkatkan resiko terjadinya stres kerja yang merupakan salah satu dari gangguan psikologis. Selain itu, kondisi tersebut dapat meningkatkan keinginan untuk keluar dari organisasi, dan rendahnya employee engagement pada pekerjaannya.

Employee engagement yang rendah membuat karyawan sulit berkomitmen, tidak antusias dalam bekerja, prestasi kerja menurun, dan tidak memiliki kesadaran tentang pentingnya keberlangsungan bisnis yang semakin kompetitif (Robinson, Perryman, \& Hayday, 2010). Dengan demikian, diperlukannya kesadaran bisnis oleh unsur manusia di dalam perusahaan agar mampu menghadapi tantanagn bisnis yang semakin kompetitif. Kondisi ini dapat terjadi jika karyawan memiliki employee engagement dalam diri karyawan sehingga mampu 
menghasilkan jasa maupun produk yang berkualitas tinggi (Robbins \& Coulter, 2010).

Employee engagement merupakan penilaian positif pada karyawan mengenai pekerjaannya yang ditandai dengan adanya vigor, dedication, dan absorbtion saat melakukan berbagai aktivitasnya (Schaufeli \& Bakker, 2004), ketiganya mampu meningkatkan rasa memiliki dan membuat karyawan terikat dengan pekerjaannya (Schaufeli, Salanova, González, \& Bakker, 2002). lebih lanjut dijelaskan bahwa, aspek-aspek employee engagement terbagi dalam tiga aspek. Vigor merupakan tinggi rendahnya semangat dan kelenturan karyawan dalam bekerja. Dedication adalah pemaknaan, kebanggaan, antusias, dan inspirasi seorang karyawan dalam bekerja. Absorption merupakan penghayatan, minat yang mendalam, dan konsentrasi karyawan serta sulit melepaskan diri dari pekerjaan.

Hasil penelitian Zulfiqor (2014) pada karyawan NET divisi produksi mengungkapkan bahwa masih terdapat $22.97 \%$ karyawan yang disengaged. Portal Human Resources (HR) pada tahun 2016 mengungkapkan bahwa karyawan di Indonesia 80\% not engaged. Hal ini juga di tunjukkan oleh Gallup Indonesia bahwa hasil survery yang dilakukan menunjukkan hanya 13\% pekerja yang fully engaged, $11 \%$ actively engaged dan sebanyak $76 \%$ tidak engaged di tempat kerjanya (Portal, 2016). Hal ini dijelaskan lebih lanjut oleh Kurniawan dan Nurtjahjanti (2016) di mana employee engagement masih dipandang sebelah mata dan belum di nilai penting oleh pekerja dan instansi yang ada di Indonesia.

Seharusnya karyawan memiliki employee engagement di dalam menjalani pekerjaannya (Kaswan, 2017). Karyawan yang engaged akan lebih lebih bersemangat dan bergairah dalam bekerja (Bakker \& Leiter, 2010). Selain itu juga karyawan akan mengoptimalkan tenaga dan pikirannya dalam menyelesaikan pekerjaan-pekerjaannya. Antony (2019) berpendapat bahwa employee engagement pada sebuah perusahaan merupakan suatu kebutuhan karena memiliki arti penting bagi perusahaan karena tingkat engaged karyawan yang tinggi akan berpengaruh besar baik pada kinerja karyawan maupun kinerja perusahaan.

Susanto, Suryamarchia, dan Widjaja (2016) menyatakan bahwa salah satu factor yang berpengaruh pada employee engagement adalah lingkungan kerja. Dijelaskan lebih lanjut bahwa dorongan kerja dan engagement karyawan akan meningkat apabila lingkungan kerja mendukung dan menyenangkan (Naidoo \& Martins, 2014). Antony (2019) menambahkan untuk menciptakan kinerja terbaik dengan menumbuhkan employee engagement pada karyawan melalui pengelolaan SDM yang baik. Employee engagement juga dipengaruhi oleh kebahagiaan karyawan di tempat kerja (Norianggono, Hamid, \& Ruhan, 2014). Hal ini sangat erat kaitannya dengan kondisi lingkungan kerja yang bersih, nyaman, dan aman. Senada dengan pendapat Sihombing (2004) bahwa lingkungan kerja yang bersih dan nyaman didapatkan melalui penerapan lingkungan kerja fisik, sehingga dapat menimbulkan rasa aman dan nyaman sehingga dapat meningkatkan kinerjanya. Menurut Albrecht (2010) hasil kerja yang meningkat menunjukkan bahwa karyawan memiliki tingkat engaged yang tinggi.

Menurut Robbins dan Coulter (2010) setiap objek yang dipersepsikan individu berbeda-beda atau tidak sama. Lebih lanjut, persepsi sangat penting dalam sebuah organisasi karena sesuatu yang dipersepsikan sangat berpengaruh pada perilaku yang akan ditampakkan. Hal tersebut disebabkan karena persepsi dapat menentukan perilaku yang akan ditunjukkan sesuai dengan persepsinya. Salah satunya, perilaku yang ditunjukan seseorang ketika mempersepsikan lingkungan kerja di perusahaannya.

Sedarmayanti (2009) mendefinisikan lingkungan kerja fisik merupakan kondisi di tempat kerja baik dalam bentuk fisik yang berpengaruh pada karyawan. Menurut Sulistyorini, Tawil, dan Meyara (2016) persepsi lingkungan kerja fisik merupakan penilaian seseorang karyawan terhadap segala sesuatu yang ada di tempat kerja seperti peralatan, mesin ataupun fasilitas lainnya. Selanjutnya, hal-hal tersebut dapat berpengaruh besar pada kinerjanya. Sedarmayanti 
(2009) membagi lingkungan kerja fisik ke dalam dua aspek, yaitu lingkungan kerja langsung dan lingkungan kerja perantara.

Siagian (2009) berpendapat keadaan fisik di tempat kerja harus dibuat senyaman mungkin karena dapat berpengaruh besar terhadap penginkatan kinerja, produktivitas dan antusias dalam menyelesaikan pekerjaan. Menurut Naidoo dan Martins (2014) karyawan yang memperspsikan positif terhadap lingkungan kerja fisik lebih termotivasi dalam bekerja dan menunjukkan tingkat engaged yang tinggi untuk bekerja. Azeem, Rubina, dan Paracha (2013) menyatakan bahwa karyawan yang memiliki engaged tinggi akan memahami tujuan dan peraturanperaturan institusi.

Norianggono et al., (2014) menyatakan apabila pencahayaan yang terlalu terang maupun gelap, sirkulasi udara yang kurang sejuk, temperatur terlalu ekstrin, tidak adanya peredam suara, pewarnaan dinding yang tidak tepat, layouting tempat kerja yang semrawut, dan lain sebagainya berakibat negatif pada persepsi karywan. Hal ini mengakibatkan, karyawan merasa tidak nyaman dan tidak bergairah dalam menyelesaikan tugas dan kewajibannya yang diberikan. Menurut Whittington, Simone, Enoch, dan Sri, (2017) karyawan yang tidak bersemangat dalam bekeja mendandakan bahwa karyawan memiliki engaged yang rendah. Hal ini ditunjukkan dengan perilaku yang tidak menguntungkan perusahaan seperti tidak bersemangat, sering tidak masuk kerja, hingga keinginan untuk berpindah ke perusahaan lain menjadi meningkat. Sehingga berpengaruh pada penurunan target perusahaan. Senada dengan hasil penelitian Anitha (2014) yang menunjukkan lingkungan kerja fisik memberikan kontribusi terhadap employee engagement sebesar $31 \%$.

Berdasarkan pemaparan tersebut, rumusan permasalahan dalam penelitian ini Apakah terdapat kaitan antara persepsi lingkungan kerja fisik dengan employee engagement pada karyawan?

\section{METODE}

Karyawan bagian produksi CV. Busana Mandiri adalah subjek yang digunakan dalam penelitian ini. Adapun jumlah subjek yang digunakan sebanyak 53 orang. Pemilihan subjek dalam riset ini menggunakan purposive sampling. Kriteria subjek berstatus karyawan tetap dan sudah bekerja minimal 6 bulan serta berusia 21-40 tahun.

Metode pengumpulan data dengan menggunakan Skala Employee Engagement dan Skala Persepsi Lingkungan Kerja Fisik. Skala Likert digunakan dalam penelitian ini dan aitem-aitem dalam skala ini dibagi ke dalam satu kelompok, favorable.

Skala Employee Engagement ada14 aitem dengan koefisien daya beda aitem bergerak dari rentang 0,295-0,704, dengan nilai reliabilitas sebesar 0,866. Sedangkan Skala Persepsi terhadap Lingkungan kerja Fisik ada 11 aiten dengan koefisien aitem total bergerak dari rentang 0,4800,625 , reliabilitas skala sebesar 0,850 . Teknik koleralsi product moment digunakans ebagai metode analisis datanya.

\section{HASIL}

Diperoleh nilai KS-Z $=0,166(\mathrm{p}>0,001)$ pada variable employee engagement dan KS-Z $=$ 0,265 ( $p>0,0001$ ) pada variable persepsi lingkungan kerja fisik yang menunjukkan bahwa skor dari masing-masing variable terdistribusi normal. Hasil uji linieritas variable employee engagement dan persepsi terhadap lingkungan kerja fisik didapatkan koefisien linieritas sebesar $\mathrm{F}=37,285(\mathrm{p}<0,000)$. Hal ini menunjukkan bahwa hubungan antara employee engagement dan persepsi terhadap lingkungan kerja fisik linier. Hasil analisis korelasi product moment diperoleh 
koefisien korelasi $\left(\mathrm{r}_{\mathrm{xy}}\right)=0,650$ dengan $\mathrm{p}=0,000$, hal ini berarti ada hubungan positif antara persepsi terhadap lingkungan kerja fisik dengan employee engagement pada karyawan. Nilai korelasi antara employee engagement dan persepsi terhadap lingkungan kerja fisik pada karyawan adalah 0,650 termasuk koefisien nilai korelasi yang kuat (Sugiyono, 2016). Hasil analisis product moment menunjukkan rxy $=0.650(\mathrm{p}<0.000)$, yang berarti terdapat korelasi positif antara persepsi lingkungan kerja fisik dengan employee engagement.

\section{DISKUSI}

Diterimanya hipotesis pada penelitian ini menunjukkan bahwa persepsi lingkungan kerja fisik menjadi faktor yang dapat berpengaruh pada employee engagement. Senada dengan penelitian Anitha (2014) lingkungan kerja fisik mampu mempengaruhi employee engagement yang dimiliki karyawan. Sedarmayanti (2009) menyatakan bahwa lingkungan kerja fisik terbagi menjadi dua aspek yaitu lingkungan kerja langsung dan lingkungan kerja perantara.

Lingkungan kerja fisik merupakan kondisi di tempat kerja dalam bentuk fisik yang berpengaruh pada karyawan baik secara langsung maupun tidak langsung, seperti peralatan kerja dan tata letaknya (Sedarmayanti, 2009). Menurut Gie (2000) jika karyawan tetap menggunakan peralatan dan fasilitas kerja yang sudah tidak pantas dipakai, lingkungan kerja kurang bersih, dan tata letak barang yang tidak beraturan, maka membuat karyawan tidak merasakan keamanan dan kenyamanan dalam menjalani pekerjaan yang berdampak pada disengaged. Kahn (dalam Albrecht, 2010) berpendapat karyawan yang disengaged secara simultan akan menarik diri dari peran kerjanya, rendahnya komitmen, sehingga tujuan organisasi sulit tercapai. Hal ini didukung berdasarkan data lapangan yang menunjukkan bahwa subjek sulit merasakan kenyaman menggunakan fasilitas istirahat di tempat kerja karena terlalu sempit, tata letak peralatan kerja menyulitkan subjek untuk menaruh dan mengambil barang, dan subjek merasa perlengkapan kerja belum memadai untuk menunjang pekerjaan, sehingga subjek mudah letih, sulit menunjukkan semangat dalam bekerja, dan sulit menunjukkan antusias untuk menyelesaikan pekerjaannya.

Sedarmayanti (2009) menyatakan bahwa karaywan akan antusias dalam bekerja apabila diberikan alat dan fasilitas kerja yang mendukung seperti suhu ruangan, sirkulasi udara yang cukup dari ventilasi, dan pencahayaan yang baik. Menurut Wulandari (2017) persepsi negatif terhadap lingkungan kerja seperti tingkat kecerahan dalam pencahayaan yang tidak baik, sirkulasi udara yang buruk, dan suhu ruangan yang berlebihan, maka hal tersebut membuat karyawan merasakan ketidaknyamanan dan kebosanan dalam bekerja. Hal ini menyebabkan semangat dalam bekerja menjadi kurang dan lebih sulit berkonsentrasi dalam menjalani pekerjaannya. Kuranya konsentrasi dalam bekerja menjadikan karyawan disengaged, hal ini menyebabkan waktu yang digunakan dalam bekerja terasa lebih lama dan tidak menyenangkan sehingga membuat karyawan banyak yang tidak masuk kerja dan tingkat turnover semakin tinggi (Schaufeli et al., 2002). Hal ini didukung berdasarkan data lapangan yang menunjukkan bahwa subjek merasa suhu dalam ruangan kerja terasa kurang sejuk, sirkulasi udara yang buruk membuat subjek merasa pengap berada di tempat kerja, dan pencahayaan yang redup membuat subjek kurang fokus dalam menjalani pekerjaa, sehingga subjek merasa waktu berjalan begitu cepat, bosan dalam bekerja, bahkan memiliki niatan untuk berhenti dari pekerjaan sekarang jika telah mendapatkan pekerjaan lain yang sesuai dengan harapan subjek.

\section{KESIMPULAN}

Berdasarkan hasil penelitian di atas menunjukkan adanya hubungan antara persepsi lingkungan kerja fisik dengan employee engagement pada karyawan. Agar dapat meningkatkan 14

Ony Sholikhatun Rukmi Putri-Persepsi lingkungan kerja fisik dengan employee engagement 
tingkat employee engagement-nya maka perlu meningkatkan persepsi terhadap lingkungan kerja fisik yaitu dengan cara memandang bahwa lingkungan yang diberikan perusahaan sudah memadai. Seperti ruang istirahat jika merasa terlalu sempit, sebaiknya individu istirahat di luar ruangan, kemudian berinisiatif menata peralatan kerja yang dibutuhkan agar memudahkan untuk menggunakannya, dan jika tempat kerja terlalu panas individu bisa membuka jendela maupun pintu kantor atau membawa kipas kecil yang menggunakan baterai untuk ditaruh di meja tempat kerjanya mengingat setiap karyawan memiliki penilaian yang berbeda terhadap suhu maupun sirkulasi ruangan. Hal ini akan membuat individu lebih engaged karena nyaman dan fokus dalam bekerja untuk mencapai hasil melebihi target yang ditetapkan dengan kualitas yang baik. Perusahaan dapat meningkatkan employee engagement dengan cara meningkatkan persepsi terhadap lingkungan kerja menjadi lebih positif, yaitu dengan cara memberikan lingkungan kerja fisik yang baik.

\section{DAFTAR PUSTAKA}

Albrecht, S. L. (2010). Handbook of employee engagement: Perspectives, issues research and practice. United Kingdom: Edward Elgar Publishing Ltd.

Anitha, J. (2014). Determinants of employee engagement and their impact on employee performance. International Journal of Productivity and Performance Management, 63(3), 308-323.

Antony, S. (2019). Pengaruh lingkungan kerja, kepemimpinan, kompensasi dan pelatihan kerja pada keterikatan karyawan hotel berbintang 4 di Batam. Jurnal Ekonomi \& Ekonomi Syariah, 2(1), 96-107.

Azeem, M. F., Rubina, \& Paracha, A. T. (2013). Connecting training and development with employee engagement : How does it matter? World Applied Sciences Journal, 28(5), 696703.

Bakker, A. B., \& Leiter, M. P. (2010). Work engagement: A handbook of essensial theory and research. New York: Psychology Press.

Gie, L. (2000). Administrasi perkantoran modern. Yogyakarta: Liberty.

Kaswan. (2017). Psikologi industri dan organisasi. Bandung: Alfabeta.

Kurniawan, B. W., \& Nurtjahjanti, H. (2016). Hubungan antara persepsi terhadap kompensasi dengan employee engagement pada karyawan PT. X. Jurnal Empati, 5(4), 732-737.

Naidoo, P., \& Martins, N. (2014). Investigating the relationship between organizational culture and work engagement. Problems and Perspectives in Management, 12(4).

Norianggono, Y. C. P., Hamid, D., \& Ruhana, I. (2014). Pengaruh lingkungan kerja fisik dan non fisik terhadap kinerja karyawan (studi pada karyawan PT. Telkomsel area III jawaBali Nusra di Surabaya). Jurnal Administrasi Bisnis, 8(2), 1-10.

Novitasari, M., Jayanti, S., \& Ekawati. (2015). Novitasari, M., Jayanti, S., dan Ekawati. 2015. Perbedaan kelelahan dan stres kerja pada tenaga kerja shift I, II dan III bagian produksi pabrik minuman PT. X Semarang. Jurnal Kesehatan Masyarakat, 3(1), 385-394.

Portal, H. (2016). Gawat! Pekerja di Indonesia 80\% not engaged, lantas apa solusinya? Retrieved from https://portalhr.com/survei/gawat-pekerja-di-indonesia-80-not-engagedlantas-apa-solusinya/

Robbins, S. P., \& Coulter, M. (2010). Manajemen edisi kesepuluh. Jakarta: Erlangga.

Robinson, D., Perryman, S., \& Hayday. (2010). (2004). The drivers of employee engagement report 408. Brington: Institude for Employement Studies. Brington: Institude for Employement Studies.

Schaufeli, W. B., \& Bakker, A. B. (2004). Job demands, job resources, and their relationship 
with burnout and engagement: A multi-sample studi. Journal of Organizational Behavior, 25, 293-315.

Schaufeli, W. B., Salanova, M., González, V., \& Bakker, A. B. (2002). The measurement of engagement and burnout: A confirmatory factor analytic approach. Journal of Happiness Studies, (3), 71-92.

Sedarmayanti. (2009). Sumber daya manusia dan produktivitas kerja. Bandung: Mandar Maju. Siagian, S. P. (2009). Manajemen sumber daya manusia. Jakarta: Bumi Aksara.

Sihombing, S. (2004). Manajemen sumber daya manusia. Jakarta: Balai Pustaka.

Sugiyono. (2016). Metode penelitian kuantitatif, kualitatif, dan $R \& D$. Bandung: Alfabeta.

Sulistyorini, R., Tawil, M. F. R., \& Meyara, S. D. S. (2016). Hubungan persepsi terhadap lingkungan kerja fisik dengan stress kerja karyawan pg jatiroto lumajang. Retrieved from https://ejournal3.undip.ac.id/index.php/empati/article/view/7528.

Susanto, F., Suryamarchia, G., \& Widjaja, D. C. (2016). Faktor-faktor yang mempengaruhi employee engagement di hotel Ibis Style di Surabaya. Jurnal Hospitality Dan Manajemen Jasa, 4(2), 552-556.

Whittington, J. L., Simone, M., Enoch, A., \& Sri, B. (2017). Enhancing employee engagement: An evidence-based approach. New York: Palgrave Macmillan.

Wulandari, R. (2017). Pengaruh lingkungan kerja fisik terhadap kinerja pegawai bidang sekretariat pada dinas perindustrian perdagangan, koperasi, dan usaha mikro kecil dan menengah provinsi Kalimantan Timur di Samarinda. Administrasi Bisnis, 5(1), 150-164.

Zulfiqor, M. (2014). Analisis faktor anteseden sebagai penentu tingkat employee engagement pada karyawan net (studi kasus pada divisi produksi tahun 2014). Jurnal Eproc, 15(4), $151-159$. 